with the radical reform of the practical part of our science. They should be discussed repeatedly. We need to speak out often, and at greater length, than we have been able to do here.

We have fearlessly ventured to portray in unvarnished truth, and with the responsibility of being held to our words, five of the weightiest questions of administrative psychiatry; questions the successful solution of which must exercise a powerful influence upon the therapeutics of insanity. May we not be misunderstood!

Is it desirable to advance in the practical treatment of the insane? for what does it profit mankind to make daily progress in theoretical knowledge, to multiply handbooks of psychiatry like mushrooms, to swell our special journals with extensive theoretical observations of all sorts, but at the same time to leave the practical part of phrenopathics, including the administrative portion, in a state of lamentable stagnation; while we reject every measure of true reform, and still vainly hold on to the rotten cable of "Routine?"

"Coupons le cable ; il est temps."

The Scientific Place and Principles of Medical Psychology. By J. Stevesson Bushnan, M.D.; Fellow of the Royal College of Physicians of Edinburgh; late Senior Physician to the Metropolitan Free Hospital ; Resident Proprietor of Laverstock House Asylum, near Salisbury.

Upos a recent occasion we took some pains to review the various significations in which the word "psychology" has been of late employed. We found that among some writers the use of this word had absolutely run wild. We pointed out that the word had not been . very long established in the language of science, and that its significance, even at present, admitted of some latitude. We expressed our opinion that the most warrantable use of the word is to signify the phenomenology of the human mind, including - l, the phenomena of knowledge ; 2, the phenomena of feeling; and 3, the phenomena of effort; but that it seemed still possible to give an extension to its meaning, so that it should include the psychology of man in the sense just indicated, or anthropo-psychology, and the psychology of the dumb creation, or eneo-psychology. If such an arrangement as this were adopted, it would nearly correspond with that which may be termed metaphysical psychology. The epithet metaphysical, as here applied to psychology, is not to be regarded as tautological or superfluous, 
because it is designed to denote that old form of the science of the pneumatology of the human mind which rests exclusively upon what is taught by consciousness; while physiological psychology includes all that can be determined upon probable evidence of the phenomonology of the functions of consciousness in the animal kingdom at large.

The title of this article, "The Scientific Place and Principles of Medical Psychology," we have borrowed from the introductory address to a course of lectures by Professor Laycock, whose work on 'Brain and Mind' we reviewed in the January number of this journal. The phrase "medical psychology" we should regard as properly synonymous with physiological psychology. And in a practical point of view, we should prefer to consider physiological psychology as the genus under which the two species, anthropo-psychology and eneo-psychology, are ranged.

But enough of preliminary definition. Our present purpose is to direct further attention to the views entertained by Dr. Laycock ; and as we are most desirous thoroughly to understand the whole scope of the learned professor's speculations, so we trust our readers will not unwillingly bear us company while we endeavour to extract from the tract before us, and from Dr. Laycock's larger work, some additional light to clear up a subject at once so obscure and so important. It appears to us that the accomplished author of the address commits the error of claiming somewhat too much for his own peculiar method in the study and cultivation of psychology. Of the vast amount and variety of topics of knowledge which Dr. Laycock's method brings within its sphere we may judge by the most superficial glance, but it does not therefore follow that that method is to be the parent of improvement coextensively with the width of range of subjects. If there be any one feature in our author's system more striking than another, it is the large extent of generalisation by which it is distinguished; nevertheless, what he unceasingly dwells upon is the improvement he expects to make in practical metaphysics. Now, the way to practical improvements in almost every department is in the opposite direction to generalisation. Thence we assert that proof is required from Dr. Laycock, beyond what he has as yet afforded, that a system so characterised by extended generalisation is likely to be at once fruitful in practical results.

If we compare the vastness of Dr. Laycock's system, as exhibited in his former work and in the lecture before us, with any reasonible acceptation in which the phrase "practical psychology" can be received, we think it will be difficult to discover any such closeness of relation between them as should entitle him to claim a pre-eminently practical character for his views.

The questions, then, under debate are-what is the essential character of Dr. Laycock's method? and what is practical psychology?

Dr. Laycock's grand aim is to establish that the mainspring is a 
teleological force-a supreme designer, not physical in character, but essentially personal, and therefore an infinite mind.

The foundation of this great generalisation is manifestly the observation that what is called MIND in man is characterised by the property of contriving means to ends. This, in short, according to the system under consideration, is the definition of mind-that which has the property of contriving or adjusting means to ends. Whenever, therefore, this property is observed to be exercised, there it is justly inferred that MIND is in operation.

Now, all the external life of the animals inferior to man, which in common language is referred to instinct, consists, for the most part, of the adjustment of means to ends; hence there is discovered an exercise of mind in the operation of such instincts. It is not necessary to suppose that mind exists in each of those inferior members of the animal kingdom; it is enough to infer that the power of exercising mental acts, under certain circumstances, is stamped upon them as a condition of their existence. Even in the vegetable kingdom there are certain acts strictly analogous to the effects of instinct in the animal kingdom ; these, therefore, must, in like manner, be regarded as indications of a power of exercising mental acts having been stamped upon them as a condition of their existence.

Here, then, are already three distinct cases, in which is exemplified the exercise of MIND in as many separate parts of nature.

We are next called upon to consider that wonderful series of processes by which, out of certain mineral elements of the earth's envelopes, the germs of organic bodies become developed into the endless variety of the vegetable and animal kingdoms. There is, beyond question, in every quarter of this animated field the most remarkable adjustment of means to ends. There is, therefore, the same evidence, as in the previous cases of the operation of MIND. Such acts as fall under this great head are known in physiology as acts of vitality - they constitute the vegetative functions of organized nature, while the acts coming under the first three mentioned cases, namely, the human power of contriving means to ends, and the analogous effects of instinct in the lower animals and in the vegetable kingdom, belong to the relative functions. Thus, organic nature furnishes four great separate forms, in which the exercise of MIND is discovered; in other words, thought, the instinct of the two organized kingdoms of nature and the operations of vitality, in all are co-ordinate exertions of mind.

It is manifest there was a period when nothing living existed on the surface of our earth. It requires some reflection to determine whether the act of power by which the first parents of organic species were introduced into the earth should be pronounced at once an operation of mind, like that by which means are adjusted to ends. There is obviously a very large distinction between the two acts or two series of acts, that, namely, by which an individual or pair of 
individuals is created possessed of certain endowments-among others, that of propagating offspring - and that by which the germ derived from such an original individual, or original pair of individuals, is developed and maintained, during a definite period, by aliment drawn from without. The two cases do unquestionably differ; but what is the nature of their difference? In the case of the first individual or first pair of individuals, an idea pre-existing in the Creator has been realised by development from the materials of the earth's envelope; whereas in the case of the germ derived from such an individual or pair of individuals, there is a series of potentialities which constitute the ends to be carried out by the adjustment of materials already existing within the sphere of its activity. But to carry out a plan is undoubtedly to adjust means to ends ; thus, in the realisation of the idea of a species, the Creator manifestly puts forth an act of mind, to whatever source the plan or idea may be attributed.

Thus, then, to the examples of the operation of mind alrealy accumulated, there is that overwhelming instance of mental power by which the earth was at first stocked with living beings.

Besides the act of development by which the pre-existing idea of a species is realised, it is discovered, by a survey of organic nature in the aggregate, that one plan pervades the whole; that there is everywhere a continuity of purpose; that, in short, amid an almost infinite diversity of development in different species, there is an unmistakeable unity of design. Thus, as the entire range of organic nature conforms in one grand preconception, the event of its appearance, as a whole, in a planet previously destitute of every living thing, is the greatest exercise of mental power which falls within the reach of man's apprehension. For it is not the mere adaptation of each species to the circumstances under which it is to live that is so wonderful, but the conformity of the particular species to one great plan, while this plan is bent in every one of these to answer the special conditions under which each severally is placed.

Thus, then, the field of organic nature presents a succession of cases in which there is an unequivocal exercise of acts of mind, or of that force which, being characterised by the adaptation of means to ends, is properly termed teleological force. Dr. Laycock's conclusion is"Mind, we have seen, is the cause of all phenomena; it is therefore the cause of all vital action and of all thought. And it is not the cause as if it were remote and occasional; on the contrary, it is an ever present, ever operating, internal force or energy. Now, since MIND, thus manifested, is but another word for the Supreme Designer and the Source of all Power, it follows that God is in a relation with all the phenomena of creation as their cause."

Up to the point where our author concludes that the power to which organic nature owes its origin is MIND, or a personal, intelligent. cause, his reasoning is unexceptionable; but it may be a subject of voL. VII. 
doubt whether he has anywhere afforded satisfactory proof according to the views which he has adopted, "that mind is the cause of all phenomena," or that there is no other influence but MIND concerned in the order and course of the physical universe.

The link which is defective in his reasoning is that, while in all that relates to organic nature the operation of mind in the sense of an agent ever adjusting means to ends is self-evident, it is not equally evident that the same kind of agency determines the arrangements of the physical universe. We pointed out this defect in Dr. Laycock's system at some length in our review of his larger work. We do not perceive as yet that he has made any effort to remedy this imperfection.

If Dr. Laycock's answer to this objection is that the same difficulty with which we charge his system really belongs as much to the old method of psychology as to his, we are ready to admit that the point of attack chosen by the opponents of the conclusion as to the personality of the supreme power from the phenomena of nature is the same; but we nevertheless affirm that the defence supplied under that old system, as far as yet appears, is infinitely better than his. According to that old system, the argument as to personality of the supreme power rests on natural intuitive truths in the human mind; and if this first principle be conceded, the argument is throughout legitimate, and the conclusion irresistible. Whereas in Dr. Laycock's method there is an obvious flaw in the reasoning, while there will not be wanting opponents who will dispute his premises. We have ourselves elsewhere stated concisely the old form of the argument in the following terms :

"In fine, there is a God; and the argument by which we reach this truth is of the most complete character. It does not amount to a demonstration, solely because, from its nature, it cannot be made to rest on necessary truths. But it is securely based on fundamental natural truths intuitive in the human mind."

"To repeat what in fuller detail was said before, these natural intuitive truths are- that every event must have a cause; that every change implies the exercise of power; and that every cause is to be measured by its effects. But in the universe the unity of the effects proves a unity in the power exerted; their unlimited character proves the unlimited nature of the power; and the manifest design in these effects proves the intelligence of the power. In a word, there is a God, who, in the beginning, created the heaven and the earth." ('Miss Martineau and her Master,' by J. S. Bushnan, M.D., p. 173.)

It would not suffice for Dr. Laycock to remark on this passage that he regards the intuitive truths referred to in it as not merely intuitive, but necessary, because he would then be reasoning in a circle; for, according to his system, these truths are 
- Medical Paychology, by DR. J. Sirevenson Bushnan. 375

only intuitive and necessary from a teleological point of view, that is, after he has established the universality of teleological MIND.

But let us look a little more into the particular working of our author's system, and let us first consider how far the method of observation and experience which is what Dr. Laycock appears exclusively to rely upon, is adopted to the successful cultivation of psychology. This is a very important inquiry, and we profess ourselves ready to adopt whatever conclusion is best sustained by a review of the whole facts concerned. In the first place, is there any room for the notion that there are instinctive beliefs in the progress of the development of man's mental operations? And here it should be remarked that a source of misunderstanding exists among inquirers into such questions, some limiting the information derived from consciousness to the state of the mental faculties after their full development in adult age; others including recollections of childhood, or even inferences from what must have occurred in childhood, during the earliest operations of the mind. It seems manifest, however, that the proper rule in the old system of psychology is to take evidence solely from consciousness in the mature state of the mental faculties, and to regard at least all inferences from what must have occurred in childhood as belonging, not to the metaphysical, but to the physiological method of inquiry - that is, to the investigation by observation and experience.

It appears to us that in the development of the mental faculties there are numerous sources of instinctive belief; and although the truth of this fact, in regard to those of an early date in the progress of the child, must rest exelusively on what we have just called physiological evidenee, yet that the existence of such beliefs at an early period serves to confirm the existence of the later instinctive beliefs which are claimed for the matured mind by the supporters of the old psychology. Mr. Stuart Mill, who is one of the most determined supporters of experience as the origin of our earliest knowledge, nevertheless says, "Truths are known to us in two ways-some are known directly, and of themselves; some through the madium of other truths. The former are the subject of intuition, or consciousness; the latter of inference. The truths known by intuition are the original premises (sic) from which all others are inferred. Our assent to the conclusion being grounded on the truth of the premises, we never could arrive at any knowledge by reasoning unless something could be known antecedently to all reasoning."

"Examples of truths known to us by immediate consciousness are our own bodily sensations and mental feelings. I know directly, and of my own knowledge, that I was vexed yesterday, or that I am hungry to-day. Examples of truth which we know only by way of 
inference are occurrences which took place while we were absent, the events recorded in history, or the theorems of mathematics. The two former we infer from the testimony adduced, or from the traces of those past occurrences which still exist; the latter, from the premises laid down in books of geometry, under the title of definitions and axioms. Whatever we are capable of knowing must belong to the one class or the other; must be in the number of the primitive data, or of the conclusions which can be drawn from these."

"Whatever is known to us by consciousness is known beyond possibility of question. What one sees or feels, whether bodily or incntally, one cannot but be sure that one sees or feels. No science is required for the purpose of establishing such truths, no rules of art can render our knowledge of them more certain than it is in itself. There is no logic for this portion of our knowledge."

"But we may fancy that we see or feel what we in reality infer. . . . A truth, or supposed truth, which is really the result of very rapid inference, may seem to be apprehended intuitively." . . .

"The perception of distance by the eye, which seems so like intuition, is thus, in reality, an inference grounded on experience; an inference, too, which we learn to make, and which we make with more and more correctness as our experience increases; though in familiar cases it takes place so rapidly as to appear exactly on a par with those perceptions of sight which are really intuitiveour perceptions of colour." ( 'A System of Logic,' by John Stuart Mill, vol. i, pp. 5-7, 3rd edition.)

With reference, then, to the existence of instinctive beliefs, let us take colour. The discrimination of colour is certainly not at first an acquired faculty. It is an instinctive or intuitive judgment as to the differences of colours. It implies an instinctive belief that red differs from green, yellow from blue; in its ruder exercise it requires no experience. It is a perfect example of a series of instinctive beliefs. The very fact of the occasional occurrence of colour blindness is a proof that it is not an acquired judgment, or dependent on experience. Moreover, the evidence of this being an instinctive or intuitive judgment is as patent to the psychologist who studies the mind by reflexion on the phenomena of consciousness as to the inquirer by a physiological method.

Let us take another example in which vision is concerned. Our knowledge of the distance of bodies is probably, as is commonly taught, the result of experience; but there is plainly no experience concerned in our judgment as to the direction of the visible point on which the optic axes meet in distinct vision. The knowledge or belief which every child quickly exhibits, that, that point is in the direction of a straight line at right angles to the surface of the cornea cannot be other than instinctive or intuitive. 
If we prick a metaphysician's heel of either school with a needle, he will at once say where the pain is felt. Does he recognise the seat of the pain by experience or by an intuitive judgment? It is by experience, indeed, he knows the relation of the point affected to the adjacent parts of his bodily frame, but he refers the pain to the point touched, altogether independently of experience. The physiologist knows that unless a particular point of the distant nervous centre were sound, and in nervous communication with the part touched by the needle, no pain would be felt; the subject of the experiment knows nothing of the conditions under which the pain takes place; his instinct merely teaches him where the pain is felt, and where he a child newly born, the pain would occur nowhere else but in the point touched by the needle. What else is this but an instinctive belief? And the extent of this belief should receive more attention from metaphysicians and physiologists than it has as yet obtained, since this law of belief cannot but exert the widest possible influence upon the development of all the faculties from the earliest infancy. Sir William Hamilton states this law in the following terms :

"The physiological law is - that a nervous point yields a sensation felt as locally distinct in proportion as it is isolated in its action from every other."

But let us proceed to some examples of the truths which in the old metaphysics are claimed as intuitive or instinctive, and therefore independent of experience. There is the order of necessary truths, of which we have instances in the propositions that the whole is greater than its part, and that two and two make four; also in the belief of personal identity. As the opposite of each of these propositions involves a contradiction, the belief in them independently of experience is justly termed necessary. In short, the human mind, independently of experience, is endowed with the power to apprehend a contradiction in terms, and this undoubtedly is the foundation of man's capacity for logic. Another set of examples of intuitive truths usually claimed for the human mind consists in the belief in an external world; in the free agency of self; the feeling that every event has a cause, and that there is an exercise of power wherever an event in nature takes place.

What the metaphysician affirms of these two orders of truths is, that they are independent of experience, and that he learns the fact by reflexion on the phenomena of his own mind. What those who adopt such views as Mr. Mill affirms is, that those truths are the result of observation and experience, and that they are best studied, like the several parts of physiology, by a like observation and experience.

We in the mean time pronounce no opinion; but this much we cannot but say, that the debate in the old manner of metaphysicians re- 
specting the claims of these propositions to be intuitive or instinctive truths has proved one of the most useful exercises ever introduced for the enlargement and strengthening of the human understanding. And this, we must be allowed to add, is one of the chief uses of metaphysical studies as a preparation for those practical departments of life in which the more refined kinds of analysis are required. It will not, then, be unreasonable to require, before we consent to Dr. Laycock's method being allowed to supplant the old system, that he shall prove, not only that that method is equally conducive with the old to the advancement of our knowledge of the human mind, but that it is equally suited for that kind of exercise of the mental faculties to which we have referred.

Now, while we acknowledge that Dr. Laycock's views are in their several parts sufficiently distinct and intelligible, we cannot but think that there is some deficiency in clearness of connexion between particular parts of his reasonings and conclusions. But a system deficient in these qualities is not well fitted to the purpose just indicated, namely, that of strengthening and enlarging the mental powers of the student. This defect of clearness in the connexion between the several parts of his system appears, in a great measure, to arise from his contrasting his own views, not with the recent systems of the old metaphysics, such as these are found in modern works and in the prelections of the metaphysical teachers of our own times, but with all that has ever been written under that old system, from the time of Plato and Aristotle downwards; the consequence of which is often an inextricable confusion in regard to the points which are really under debate. We desire to call Dr. Laycock's attention to this defect, as we deem it, because it interferes very much with the good which really is in his system from being made either apparent or available.

We think we shall be able to illustrate what we mean without departing from the point now under consideration, namely, how far our judgments are intuitive or instinctive, and how far the result of observation and experience. We shall first cite a passage from Mr. Stuart Mill, and then some passages from Dr. Laycock, with the purpose of discovering how far the latter, under a particular head, really debates such questions as are held in the present day to rank under that head.

"Of the science which expounds the operations of the human understanding in the pursuit of truth, one essential part is the inquiryWhat are the facts which are the objects of intuition or consciousness, and what are those which we merely infer?... Its place is in that portion of mental philosophy which attempts to determine what part of the furniture of the mind belongs to it originally, and what part is constructed out of materials furnished to it from without. To this science appertain the great and much-debated questions of the 
existence of matter; the existence of spirit, and of a distinction between it and matter; the reality of time and space, as things without the mind, and distinguishable from the objects which are said to exist in them. For in the present state of the discussion on these topics it is almost universally allowed that the existence of matter or of spirit, of space or of time, is in its nature unsusceptible of being proved; and that if anything is known of them, it must be by immediate intuition. To the same science belong the inquiries into the nature of conception, perception, memory and belief, all of which are operations of the understanding in the pursuit of truth. ... To this science must also be referred the following and all analogous questions :-To what extent our intellectual faculties and our emotions are innate ; to what extent the result of association. Whether God and duty are realities, the existence of which is manifest to us $\grave{a}$ prior $i$ by the constitution of our rational faculty; or whether our ideas of them are acquired notions, the origin of which we are able to trace and explain; and the reality of the objects themselves, a question not of consciousness or intuition, but of evidence and reasoning." ("A System of Logic,' by John Stuart Mill, vol. i, pp. 7, 8.)

Under Dr. Laycock's section entitled "Definition of Intuitive Ideas and Necessary T'ruths" we should expect to find a distinct statement of his views respecting some of the topics referred to in the quotation from Mr. Mill, or on some other topics having, at least, an alliance with these. Nevertheless we have felt disappointed, nor do we imagine our readers will feel otherwise when they peruse the following quotations :

"Metaphysicians have discussed in various ways, and under various phases, the question whether all our knowledge is the result of experience; or whether, by the constitution of our nature, we have knowledges independently of experience, or which only require experience for their development. According to the one view, the mind is a tabula rasa, or like a sheet of white paper on which experience writes its teachings; according to the other, there are innate ideas, powers, or capacities, in the tabula or paper, which are there independently of experience.

"Whenever these questions have been discussed according to the usual method-that is to say, when the sources of our knowledge have been inquired into without regard to the laws of action of the vital forces in those corporeal structures in virtue of which we acquire any knowledge at all-incurable confusion has been made the result. The two great sects between which philosophy has been divided have both truth on their side ; that they disagreed at all was due, in fact, to the one-sided view each took of the questions. In particular, in discussing the various moral and philosophical questions to which the problem has given rise, the phrases intuitions and intuitive ideas have been used synonymously with the terms intuitive 
truths and necessary truths. Now, these terms are not, in fact, synonymous, if we look at mental phenomena in their correlations with vital changes. Strictly speaking, an idea, considered as a causal agent, is neither true nor false; we might with equal propriety say that the force of gravity is true or false. . . Truth, then, as a quality, is a derivative, contingent, and variable idea; a special truth is the knowledge of an idea in its real relations-i.e. is a cognition of accurate experience. The essential quality of an idea is its necessity, in which it correlates law and force. Hence metaphysicians use the term necessary (literally nerer-ceasing) correlatively with terms applicable to all the great laws and forces of nature." ("Mind and Brain,' vol. i, pp. 287, 288.)

Surely Dr. Laycock will not seriously say that in placing a passage such as that just quoted before young students of mental science, he is fairly representing the state of the old metaphysics at the epoch when his volumes were published. He speaks of incurable confusion being introduced into the subject by the old mode of dealing with it, but the phrases and terms he has himself ememployed in the passage above quoted will be liable to create greater confusion. What recent author will he produce who has insisted upon innate ideas? What recent author will he refer to who has denied innate capacities? Does he regard ideas and caracities as s;nonymous terms? We believe he will find no one in recent times to dispute that the mind is originally a tabul a rasa - a sheet of white paper. The only question, as plainly appears by Mr. Mill's statement of the case, at present debated is, what is the nature and extent of the characters which appear on the white paper, when impressions begin to be made upon it in the exercise of the senses and the subsequent exercise of the mental faculties? Is there any notion more familiar to physiologists than that of potentiality? It is hardly possible to suppose that Dr. Laycock can think it conducive to clearness of statement to confound the potential with the actual, by treating innate ideas as synonymous with capacities for ideas.

The mind of the infant is undoubtedly a tabula rasa-a sheet of white paper-but that tabula rasa already holds within itself a potentiality of a future, or, what is the same thing, susceptibilities of all that is to constitute the mental history of the individual, ready to be developed when the appropriate conditions arise. The view adopted in general, at present, on this point, is clear and distinct. Nothing is or can be present to the mind until it is brought before the mind under a condition which originates independently of the mind. Thus, a red surface comes before the eye-an impression is made on the retina-the optic nerve carries the impression to a certain tract of the nervous centre- a sensation arises, and this state of consciousness is an operation of mind-it is referred to the points of the retina on 
which the impression is made, while the consciousness is attended with a belief of its own externality : a condition has arisen under which, by its essential constitution, the mind wakes into action. There are ideas, but they are not innate or intuitive. They follow on the application of an external condition. Next, let us suppose a green surface presented to the eye. The like phenomena take place. There is in the mind the potentiality of discerning the difference between the effect of the red surface and that of the green. This is a distinct idea. But it is not an intuitive idea-it is not an innate idea ; it had no existence, except in potentiality, until the requisite conditions were applied. We will concede to Dr. Laycock that it is a necessary idea, in so far as it necessarily results from the constitution of the human mind under the application of the conditions concerned. But this is not the kind of necessity referred to in the debate of the questions under consideration. It is plainly a logical necessity, not a necessity in the order of nature. Whatever is, is-is a proposition of logic; and Dr. Laycock's necessity, as applied to ideas in the above passage, falls under that head. If the human mind be constituted after a certain plan, then it is constituted after that plan, and no other. But there was no necessity in the order of nature for that plan. It might have been different.

Before saying more on this matter we will cite the next passage to that already quoted from Dr. Laycock's chapter:

"Looked at from the teleological point of view, all truths are obviously necessary truths, inasmuch as what we term truths are only our cognitions, intuitional or acquired, of the fixed, immutable, and necessary order of events in creation, or of the correlative forces upon which these events depend. Hence it is the quality of necessity which correlates all truth whatever. But we can distinguish between universal or general and particular or derivative truths, just as we distinguish between general and derivative ideas and general and derivative laws and forces. Now, as these are variable and contingent, because derivative, so there are truths which are correlatively variable and contingent, because derivative; these are the truths of experience. The fundamental truth of mental science is that mind regulates the application of force to desirable results. Within this generalisation all the other truths of mental science are contained as derivative truths. Or if we examine the order of events as determined by the law of design, in discovering the results of that order we learn what are the fundamental or derivative ideas and truths.

The truths are none other than the generalisation of science or of experience as to that order; e. g. it is a truth that all men die, that life is finite, that air has weight, that we see with our eyes, hear with our ears, \&c. The ideas are none other than the result converted into cognitions, and considered etiologically and apart from the phenomena, as the law by which events were made to succeed each other in a 
fixed order. Thus, while an idea is that which conceivably and necessarily precedes the order of events in the mind of the designer, as cause, the truth is that which expresses the results of the order, as the manifestation of the idea in creation. The idea expresses the nou-menon-i.e. the order as it is thought or designed; the truth expresses the correlative phenomenon-the thought realised, or the order effected. Hence the idea is necessarily potential, the truth necessarily actual. It follows from these premises that ideas and truths correlate the laws of creation; that fundamental ideas and truths correlate fundamental laws ; derivative ideas and truths correlate derivative ideas and laws." (Laycock, ibid., pp. 288-90.)

It is obvious that all this is nothing more than a commentary on the logical proposition already referred to, viz., what ever is, is ; and that no part of it has any reference to the question indicated by our author at the commencement of the chapter, namely, "whether all our knowledge is the result of experience, or whether, by the constitution of our nature, we have knowledges independently of experience, or which only require experience for their development." Our author next proceeds as follows :

"Turning now to an examination of the distinction made by metaphysicians betwcen a priori truths and the truths of experience, we find that the distinction is the same as that made between the universal and the particular, the absolute and the contingent, the primary and the derivative, and the like. Examined teleologically from this point of view, the truths of experience are like those derivative results of general laws and forces which we attributed to chance; they are cognitions in which we do not perceive the absolute and the universal; they are generalisations in which the fact that they are intuitive or fundamental is not expressed or recognised. It is very obvious, then, that the truths of experience, when attained, are logically as necessary truths as the phenomena of so-called chance are logically necessary phenomena. A truth of experience ceases, therefore, to have the quality of uncertainty when the general truth from which it is derivative is detected and formalised." (Laycock, ibid., p. 290.)

Here, notwithstanding the promising outset of the paragraph, the author approaches no nearer to the real question at issue. It is quite true that the truths of experience are necessary truths so long as the law under which they fall continues unchanged. But that manifestly is merely a necessity of logic-not a necessity in universal nature. An unsupported stone falls to the ground of necessity so long as the law of gravitation remains in force. But is the law of gravitation a necessity of nature? Is it not possible that gravitation may be conditional, like the magnetism of a mass of soft iron under the influence of galvanic currents, which magnetism comes instantly to an end the moment the galvanic currents are interrupted.

Perhaps Dr. Laycock will tell us that his views are limited to 
things as they are. We know that it is a common aphorism at present to say that inductive science has nothing to do with the origin of things or with anything else than things as they are. But as there is no teleology in the systems of those who profess this aphorism, we trust that Dr. Laycock has in this respect nothing in common with them. If Dr. Iaycock regards his "teleological force" a merely directive force, and in no respect author of the forces of nature, we fear his system will fail to realise the conception of a Being with such attributes as we are entitled to demand in the Creator of the universe.

We wish the author would revise his use of the word "necessary" throughout the work. There can be no doubt that many misconceptions of his views must be the result of his frequent use of that word, without sufficient qualification or explanation.

There is no word which at present requires to be more carefully defined in philosophical speculations than this word necessary. We would remind Dr. Laycock that there has been much discussion in recent times on the question whether cause and effect be necessarily connected; and that we very commonly hear David Hume's doctrine approved of-namely, that there is no necessary connexion discoverable between cause and effect.

When Hume taught this doctrine he had no intention of denying what Dr. Laycock has so laboriously inculcated in the passages quoted above; that is to say, he did not deny, if one thing is truly called a cause and another thing as truly called an effect, that there is a necessary logical connexion between them. What he denied, for example, is that there is any necessary connexion between the production of carbonate of magnesia in the form of a white precipitate when a solution of Epsom salts is mixed with a solution of carbonate of soda. If Dr. Laycock say that, if the whole laws of chemical attractions were known, it would be seen that the connexion between the antecedent and the consequent is necessary, he will be obliged to add, "so long as things remain as they are at present ;" for if it be denied that infinite power might have established a different law, then necessity is made supreme in the universe.

We quote the paragraph which follows, where we think Dr. Laycock fairly goes into mysticism :- "If we apply the fundamental law of all cognition to an elucidation of this question, we cannot but see that, in the widest sense of the term, all truths whatever must be truths of experience, for conscientiousness itself is but an experience of the vital changes within us. We do not even know that we exist as one, out of relation to something else. Now, a knowledge of that relation implies an anterior cognition of self and not-self, which cognitions can only be results of the teleiotic or teleorganic changes going on within us to that end. Mr. Mill, therefore, has rigidly attributed even our ideas of number to experience ('System of Logic', book ii, chap. v, vi), if the term be used in the sense here indicated; for it is obvious 
that a man can only know himself numerically as one by knowing that he is one in numerical relation to another one, or to several ones. In his own consciousness he has the intuition of two-viz., his mind and his body. An organism devoid of these intuitions is, mentally, non-existent-it is 0 . "The first form of the expansion or manifestation of the mathematical monas, or of 0 , is +- . The +- is nothing else than the definition of 0 . 0 is the reduction of the positive and negative series of numbers upon which the whole of arithmetic depends. A series of numbers is, however, nothing else than a repetition of $a+1$ or $a-1$; consequently the whole of arithmetic reduces itself to + 1-l.' (Oken, 'Elements of Physico-Philosophy,' translated by Tulk.) The same law applies to our cognitions of things in space or time. It is of no consequence by what sign we indicate the two things in relation. If it be $\mathbf{A}$, then $\mathbf{A}=\mathbf{A}$. That is, $\mathbf{A}$, as known in one portion of space or time, equals $A$ as known in another portion of space and time. The two states of consciousness differ only, in fact, as to the different relations of the $A$ to space and time. But to the application of this difference a double experience of $\mathrm{A}$ in space and time is needed, and a synthetical comparison of the two experiences. This means nothing more than that experience is reduced to its simplest element; it is mind in synthesis with organization-mind active." (Laycock, vol. i, pp. 290-291.)

What possible connexion has this with the simple question with which we set out, namely, "whether all our knowledge is the result of experience; or whether, by the constitution of our nature, we have knowledges independently of experience, or which only require experience for their development"?

In the beginning of this passage Dr. Laycock tells us that all truths whatever must be truths of experience; yet he cannot but apprehend that this use of experience is totally different from the established use of it in the discussion of the question under consideration.

Moreover, when the author says that the "cognition of the relation of self and not-self can only be the results of the teleiolic or teleorganic changes going on within us to that end," he most plainly says, in the sense well understood in the discussion of this question, that such a cognition is an intuitive truth wholly independent of experience for its origin.

Our author in this passage next gives his approval of Mr. Mill's views as to number, but with a qualification which proves him to be of a totally different opinion from Mr. Mill. There is another example of Dr. Laycock's tendency to perplex us by refusing to adopt the language of metaphysical discussions in the sense in which it is of now established use.

Mr. Mill is the most determined supporter of the view that the sciences of number and quantity rest, not on necessary truths, but on truths deduced from observation and experience. Now, the qualification made by Dr. Laycock is that Mr. Mill is right if he believes that, 
by telieolic changes within us, the cognition of number exists potentially in the mind " antecedently to the act of experience on occasion of which it is first actually elicited into consciousness." Mr. Mill most distinctly entertains no such qualification. The passage in the last sentence marked as quoted is from Sir William Hamilton, and is introduced by Dr. Laycock, manifestly with approbation, in a subsequent part of the chapter we have been considering. But what is the sense of the word "experience" in that passage? Sir William Hamilton most distinctly makes it appear that such an act of experience as is here referred to is not experience as opposed to intuition, but the single act of experience which constitutes the condition on which the possession of an intuition is discovered.

But to proceed with what remains of the last passage quoted from Dr. Laycock-he goes on to say that a man has originally the intuition of Two in his mind and his body. We doubt this altogether. We do not think that man founds number upon his mind being one, and his body another one. We strongly suspect that self is from the first one, uniting both mind and body, and that the distinction of mind from body is an ulterior effort of thought.

An organism devoid of these intuitions, that is, mind and body, is $=0$. Hence, according to this reasoning, a majestic oak, the monarch of the wood, being an organism destitute of the aforesaid intuitions, is $=0$.

With respect to Dr. Laycock's quotation from Oken, without questioning its truth, what has it to do here! If it explain the origin of numbers in the human mind, it must be in understandings very differently constituted from those commonly possessed by the ingenuous youth such as we have come in contact with in this country. They do not profess to understand intuitively the language of symbols, and generally think it time enough to read such language when they study algebra.

With respect to $A$ being equal $A$, whether known in one portion of time and space or in another-the conclusion from which is that the simplest form of experience is mind in action-we think Dr. Laycock's pupils would have had more distinct ideas imparted to their minds if he had said- "Gentlemen, you remember that A was an apple-pie; that $\mathrm{B}$ bit it, that $\mathrm{C}$ cut it, that $\mathrm{D}$ divided it, that $\mathrm{E}$ ate it. Now, $\mathrm{A}$ is an object, while B, C, D, E are so many different states of consciousness, so that the biting, the cutting, the dividing, the eating, are so many distinct and separate acts of experience."

Our author, we have no doubt, for such remarks will reproach us with shallowness and inability to penetrate the profoundness of his views; but we feel confident of this, that whatever may be the grasp of Oken's intellect in respect to the general economy of the universe, his speculations as to number have nothing to do with the subject of the chapter (so often already cited) which we have been criticising. 


\section{The Scientific Place and Principles of Medical Psychology.}

To cite that subject once more, the question is "whether all our knowledge is the result of experience; or whether, by the constitution of our nature, we have knowledges independently of experience, or which only require experience for their development ;" nevertheless, after leading us to believe that he holds the side that all our knowledge is the result of experience-Dr. Laycock most obviously adopts the opposite side, as the following quotation most clearly demonstrates :

"We know that there are potentially present in the man a series of universal, fundamental, and necessary ideas, correlating equally universal, fundamental, and necessary cognitions or truths, with which the faculties are necessarily busied in all present states of consciousness, and which, becoming active during each state, are the necessary causal elements of the thoughts and acts." (Vol. i, p. 299).

We have exhibited a view of some of the learned author's doctrines, and have also afforded a specimen of his mode of treating a special subject in detail, with the purpose of enabling our readers to judge how far his system is a suitable foundation for practical metaphysics. For our own part, we regard Dr. Laycock's system as, in a great many respects, good; but at the same time we have seen too much reason to think that there are defects in its development.

We look on his system as essentially a physiological examination of that part of nature in which the more permanent forces and substances existing at the earth's surface are made subservient to the adjustment of an infinite variety of ends in the production of new forms and motions. To this part of nature psychology belongs, and we have little doubt that the kind of investigation to which such a system must lead is favorable to the improvement of the philosophy of the human mind. But we cannot concede to our author that his system, as it exists in this work, greatly transcends the old methods of the metaphysicians, as a study fitted to improve the understanding and to give a new culture to the mental faculties.

What are practical metaphysics? What but a knowledge of the ordinary faculties of the mind, of the general laws under which these faculties operate, and of the modifications which these laws are apt to undergo in individuals; what but a kuowledge of the appetites, desires, benevolent and malevolent affections of our human nature, of self-love, of moral judgment and obligation, and of the circumstances under which these are exalted, confirmed, or subverted.

How Dr. Laycock should consider his system in its present state pre-eminently fitted to teach young men practical metaphysics, such as to the points here indicated, we are entirely at a loss to comprehend. A principal use of a course of metaphysics to a student, whether his destination be to medicine, law, or divinity, is to enable him to understand the sense in which certain words are commonly used, when his professional pursuits carry him into disquisitions nearly bordering on the melaphysical. How would such a student 
fare who had applied himself, however diligently, to Dr. Laycock's work, but to none other? We fear that the knowledge which he would thus acquire would not enable him to understand the ordinary sense in which many terms denoting states of mind in relation to questions regarding human character, are commonly employed, and would not afford him such an insight into psychology as would be of practical use to him in his professional pursuits.

Dr. Laycock's system is in no sense practical. In its present state it is a purely speculative view. It is on its trial. It cannot be of practical use in the ordinary sense of that term until it be more or less generally adopted; and in order that it may, if sound, be generally adopted, we are most desirous that it should receive fair discussion.

Laverstock House, Salisbury.

Cases of Death in Epilepsy from Suffocation, caused by the regurgitation of food from the stomach into the larynx, \&c. By JosEPH LALOR, M.D., \&c.

THe three following cases are examples of death from the cause above stated, which appears not to have received much notice or attention from writers on epilepsy :

CASE 1.-Margaret Phelan, æt. 21 years, inmate of the Kilkenny District Lunatic Asylum, labouring under dementia, with epileptic fits, recurring about once each month at the catamenial period, was attacked with one of these fits after supper on January 15th, 1856, in which she died suddenly and unexpectedly. She had been placed by the attendants in the usual position on her back. I was not called to see her till after her death, and on making a post-mortem examination I found a considerable quantity of semi-fluid bread and milk in the trachea and large bronchi, which had apparently regurgitated from the stomach.

CaSE 2.- John Carpenter, an epileptic, æt. 55 years, who had been an inmate of the Richmond District Lunatic Asylum since September 15th, 1851, died about 8.30 a.m. on the 27th December, 1857, under the following circumstances. About two minutes after he had finished a hearty breakfast of stirabout and milk he was seized with an epileptic fit, commencing, as his fits usually did, with a slight scream. Being caught before he fell to the ground by the attendants, he wås laid on his back. Whilst in the fits, in the early part of the seizure, stirabout was observed coming from his mouth and nostrils, having worked up apparently from the stomach; 